\title{
Helping the young visually impaired: a view from the community
}

\author{
Daphne V Keen
}

The quality of assessment and early management of handicap has been greatly improved with the integration of children's health and educational services into district handicap teams. However, it would seem that visually impaired children and their families experience additional problems resulting in the failure of our services to meet their specific needs.

Problems in service provision to parents The recently published report, Blind and Partially Sighted Children in Britain - the RNIB Survey, ${ }^{1}$ provides evidence that the majority of parents have found problems in obtaining information and advice about their child's condition. Among the gaps in provision it identifies are:

(1) Not ever receiving an adequate and comprehensible explanation of the disability (60\% of parents).

(2) Parents feeling they had to go and search for everything themselves $(76 \%)$.

(3) The lack of genetic counselling $(80 \%)$.

(4) Having nobody knowledgeable to talk to at the greatest time of need soon after diagnosis (over 60\%).

(5) The lack of specialist advice on crucial and basic problems of infant management such as feeding, toilet training, early mobility, and language development (73\%).

In fact, only $5 \%$ of parents felt they had received all the help they needed.

Problems in service provision to children '... the impediment of blindness could be discerned at every point in development at which representational intelligence would lead the sighted child into the organisation of an object world'. 2

The central role of vision in coordinating and integrating sensory input of all kinds is not always appreciated. Its impairment can affect all aspects of a child's early development. Over half of visually impaired children have one or more additional disabilities such as impaired hearing or speech, physical handicaps, or learning difficulties. ${ }^{1}$ This means the visually impaired child has very complex developmental problems requiring active management.

There is now strong evidence for promoting the active development of residual vision in the first year of life. Specific visual development programmes, compared with general developmental programmes, have been shown to result in significant gains in visual acuity and function with a positive effect on general development, in children with most types of visual disorder and all degrees of impairment, with or without additional handicap. ${ }^{3}$

Without such programmes there is the possibility of loss of vital potential development in the early years. Nevertheless, the management of the very young suffers as a result of the fragmentation of services and the lack of a multidisciplinary approach.

Families of children who are suspected of having poor vision make contact with the medical services in a variety of ways. The routes of referral depend both on local factors and the presenting problem, and so their first point of contact may be the hospital paediatric services, child development centre, or ophthalmologist.

In many districts, ophthalmologists would not routinely refer on an apparently 'normal' infant for full paediatric assessment or genetic counselling. Nor do paediatricians and the child development teams always refer children, whose visual impairment is one of other handicaps, to peripatetic specialist teachers although it is the latter who organise and deliver the main services for visually impaired children. The peripatetic teaching service for the preschool child can exist quite precariously at the edge of these educational provisions and isolated from the district handicap team and hospital services.

Consequently, professionals are not always aware of the role of others who may be involved in a child's care.

\section{An approach to integrated service provision}

This lack of integration makes it impossible to devise programmes for the systematic promotion of visual and general development within a multidisciplinary developmental context. However, I would propose that most districts could easily develop this approach with some reorganisation of their existing expertise and resources.

Our experience in Doncaster (population just under 300000 ) may provide a useful model for other smaller districts. A joint 'vision clinic' was recently set up under the consultant 
community paediatrician, bringing together previously separate services to pool expertise and resources and develop integrated developmental programmes and parental support.

The clinic team consists of two members of the child development centre (the consultant community paediatrician and preschool teacher responsible for supervising the Portage scheme), together with two peripatetic teachers for the visually impaired and the social service department social worker with responsibility for sensory impairment (who is also a parent of a multiply handicapped child). This brings together the skills of developmental paediatrics, preschool educational/ developmental assessment, and home based developmental programmes for learning disability, visual assessment and stimulation, counselling and parental support, respectively.

The clinic is held every $6-8$ weeks on educational premises where specialist play and multisensory stimulation equipment is available. In this setting the child receives medical, general developmental, behavioural, and visual function assessment.

New cases are allocated to the clinic after discussion by the team. There is an enormous annual variation in the number of children and their degree of handicap but we expect to consider on average 4-6 new cases per annum and take on those who are not profoundly handicapped.

The team invite other paramedical or educational staff to join us on an ad hoc basis, depending on the child's problems. This is helpful where there are additional handicaps. For example, a potential conflict of therapeutic approach and confusion for parents was avoided by working with the physiotherapist of a child with a right hemiplegia and a right hemianopia who needed encouragement of visual fixation and following in the left fields and work to develop awareness of the right side of the body.

Discussion of psychological problems like fears or phobias relating to touch, movement and sound, obsessive behaviours, and overprotectiveness have been helpful in shaping physiotherapy or sleep management programmes. Similarly, combining our knowledge about the differences between the development of object permanence through sight, sound, and touch has been valuable in understanding problems like separation anxiety and feeding difficulties.

The clinic session aims for a consensus about the key developmental/visual deficits needing intervention, and the development of a home based programme based on the Oregon project $^{4}$ as a guide but incorporating specific advice of other professionals. We retain the recording system of Portage for both its clarity and consistency for home visitors. The programme is supervised and developed through weekly home visits between clinics, by either the Portage supervisor or the specialist teacher depending on the child's overall developmental needs. Joint home visits with other therapists have been beneficial in coordinating approaches.
Parents are often confused because they have been told about their child's disability extremely badly and in a way they find difficult to relate to what they know of their own child. It is not uncommon to be presented with a visually alert infant whose parents have been told she or he is 'blind'.

These problems arise because ophthalmology, education, and paediatric departments can function quite separately, with ophthalmologists being expected to provide just a diagnostic service and receiving little feedback about their patient's general progress or other handicap. We feel it is particularly important to feed back regularly our observations on the child's general and visual progress to the child's orthoptists and consultant ophthalmologist.

At a time when parents will be adjusting to the loss of their 'normal' child it will be important to stress the positive contribution they can make to their child's development by beginning to understand the nature of their child's problem and be guided in their approach to compensating for their handicap. There are some excellent publications at low cost that are a useful adjunct to such counselling and we feel it is important that the team is able to give each family something they can keep to read and reread at home.

Two publications that parents have found particularly useful are Getting it all together, ${ }^{5}$ which addresses the needs of the multiply handicapped baby and Show me what my friends can see, $^{6}$ which describes visual stimulation programmes. We have found that the Vision Clinic has been of benefit to both professionals and parents. It has not only enhanced our understanding of complex handicap, but has also stimulated interprofessional interest, cooperation, and dialogue.

An unexpected consequence of combining styles of work has been the dissemination of the structured approach of Portage. This has enabled a number of professionals of different disciplines to begin to feel able to contribute to and supervise the developmental programmes. As a result we expect to be able to provide a service to greater numbers of children in the future.

The clinic has proved to be an ideal place to demonstrate to parents their child's visual function, explain their developmental needs, engage parents in active participation in developmental programmes, and offer practical guidance. It is well placed to provide the access to those two main sources of information parents find most valuable, the medical expert and the school teacher. ${ }^{1}$ In developing an integrated service we are hoping to begin to address problems in service provision to both parents and child.

\section{Conclusions}

Although there may be serious problems in service provision to visually impaired children and their families, there are probably, in most districts, sufficient skills and expertise within existing teaching support services, Portage schemes, child developmental centres, and social service departments to form specialist 
vision teams that can address these issues. Community paediatricians can have a crucial role here. Working at the interface with each of the agencies concerned with special needs, they are well placed to be a focus for the mobilisation of resources, continuing multidisciplinary assessment, and counselling support that families require.

I would like to record the invaluable contribution of Mrs Gill Lees, Doncaster Portage coordinator, and Mrs Beth Howley and Mr Gerald Reed, peripatetic teachers for the visually impaired, who shared the vision of an integrated service and whose enthusiasm and commitment made this project possible.
1 Walker E, Tobin M, McKennell A. Blind and partially sighted children in Britain: the RNIB survey. Vol 2. London HMSO, 1992.

2 Fraiburg S. Insights from the blind. London: Souvenir Press, 1977.

3 Sonksen P, Petrie A, Drew K. Promotion of visual development of severely visually impaired babies: evaluation of a ment of severely visually impaired babies: evaluation of a 1991; 33: 320-35.

4 Brown D, Simmons V, Methvin J. The Oregon project for visually impaired and blind preschool children. 4th Ed. Oregon: Jackson Education Service District, 1991.

5 Bull M. Getting it all together. A guide for parents of babies who have other disabilities as well as very limited vision. Burwood Monograph No 1. Australia: Royal Victoria Institute for the Blind, 1991.

6 Sonksen P, Stiff B. Show me what my friends can see. London: The Wolfson Centre, 1991. 